\title{
RADIATION THERAPY FOR BREAST CANCER
}

\author{
MARTINA MIKULANDRA ${ }^{1}$, IVA BOŽINA ${ }^{1}$ and LIDIJA BEKETIĆ-OREŠKOVIĆ ${ }^{2}$ \\ ${ }^{1}$ Department of Radiotherapy and Internal Oncology, University Hospital for Tumors, \\ University Hospital Center Sestre milosrdnice, Zagreb; \\ ${ }^{2}$ Department of Clinical Oncology, School of Medicine University of Zagreb \\ and Department of Radiotherapy and Internal Oncology, University Hospital for Tumors, \\ University Hospital Center Sestre milosrdnice, Zagreb
}

\begin{abstract}
Summary
Radiation therapy represents an important aspect of breast cancer treatment. Application of irradiation reduces the incidence of local disease recurrence and improves overall survival of breast cancer patients. Studies have shown that adjuvant irradiation after breast-conserving surgery has the same result as a mastectomy, so adjuvant radiotherapy enables sparing surgery in breast cancer patients. We will review the mechanisms, indications and methods of the whole breast irradiation, as a standard approach to the treatment. The main directions and controversies of today's research will be shown, primarily the introduction of hypofractionation, i.e. distribution of high daily doses of irradiation in a shorter overall period of treatment, as well as the application of partial breast irradiation, i.e. irradiation of a part of the breast instead of postoperative irradiation of the whole breast. Further molecular analysis of tumor biology will lead to the new prognostic and predictive parameters, and thus to the further personalization in the field of breast cancer radiotherapy.
\end{abstract}

KEY WORDS: breast cancer, radiotherapy, breast-conserving surgery

\section{ZRAČENJE U LIJEČENJU RAKA DOJKE}

\section{Sažetak}

Radioterapija je koristna u liječenju raka dojke. Smanjuje pojavu lokalnog recidiva i produljuje preživljenje. Studije su pokazale da adjuvantno zračenje nakon poštednog kirurškog zahvata ima iste rezultate kao mastektomija i omogućuje primjenu poštedne kirurgije. Kao standardni pristup liječenja prikazani su mehanizmi, indikacije i metode zračenja cijele dojke. Razmatrani su smjerovi i kontroverze istraživanja, hipofrakcioniranje, (primjene većih dnevnih doza u kraćem ukupnom vremenskom razdoblju) i djelomično zračenje dojke, umjesto standardnog poslijeoperacijskog zračenja cijele dojke. Dodatne molekularne analize biologije tumora dovest će do novih prognostičkih i prediktivnih čimbenika, a time i do dodatne personalizacije $\mathrm{u}$ području radioterapije raka dojke.

KLJUČNE RIJEČI: rak dojke, radioterapija, poštedna operacija dojke

\section{INTRODUCTION}

The role of radiation therapy in the treatment of breast cancer has long been known important. Adjuvant radiation therapy reduces the likelihood of local recurrence after surgery and increases the overall survival of patients $(1,2)$. The importance of radiation therapy in the treatment of breast cancer may be the most obvious in the fact that without this form of adjuvant treatment, breast sparing surgery in many cases would not be possible. Specifically, it has been shown that the percentage of local 
recurrence after treatment with a combination of breast sparing surgery and adjuvant radiation is equal to the percentage of recurrence after mastectomy (1). So adjuvant radiotherapy after breast sparing surgery is today an essential component of treatment for early stage breast cancer. In locally advanced disease, adjuvant radiation therapy also significantly increases local disease control and survival of patients, especially in patients with tumor metastases in axillary lymph nodes (2). In patients with metastatic disease radiation therapy is an essential part of palliative treatment.

\section{General principles of radiation therapy}

Irradiation is in the most cases carried out by the high energy photons produced in linear accelerators. Linear accelerators are devices that essentially function as complex cathode ray tubes - a part of the accelerator called an electron gun, fires electrons into a strong electromagnetic field inside the tube where they accelerate to high speeds, and so accelerated electrons hit the target in and phenomenon called "breaking radiation" or releasing high energy $\mathrm{X}$-rays $(\mathrm{MeV})$. Then, the resulting $\mathrm{X}$ rays are formed by the collimator into the desired (default) bundles, and turning the head unit directed in the desired direction.

Going through the tissue of the patient, Xrays or photons interact with the matter, producing different effects. In simple terms, megavolt photon radiation will, like billiard balls, hit the electron of an atom, handing him some of his energy sufficient to release an electron, and continue its journey in a changed direction (so-called, Compton effect) with further interaction until it consumes all of his remaining energy. So formed ion, and the released electron are also involved in a number of interactions. The radiation of energy greater than $1.02 \mathrm{MeV}$ leads to the effect known as "pairing". Specifically, in contact with the electric field of the atomic nucleus photon decays into a electron-positron pair, whereby the electron continues its path causing further ionization, and the positron, which is unstable, connects with another electron, thus creating a new pair of photons, each having the energy of $0.51 \mathrm{MeV}$.

The consequences of these reactions are the ionizations and creation of unstable molecules and free radicals within the cells of the organism. This results in a number of physical and chemical reactions that lead to the damages of all cell structures, including proteins, lipids and deoxyribonucleic acid (DNA). The key damage are the double- strand DNA breaks, inhibition of cell replication and reproduction.

The higher dose of radiation means increased destrucion of tumor cells, but unfortunately also healthy cells and tissues can be damaged. The goal of irradiation is to destroy the maximum number of tumor cells, but to spare the normal tissue as much as possible. It is therefore necessary in the radiation radiation planning to define the target tumor tissue more precisely and to develop such a radiation plan that will allow maximum sparing of the surrounding healthy tissue.

In order to achieve the above objectives, in addition to the total dose of radiation, it is extremely important to determine the ratio of the total dose and the time in which the patient will receive this dose. This division of the total irradiation dose into daily doses that the patient receives during a specific time is called "fractionation." Fractionation is the best way to use the different nature of the tumor and healthy cells, or different periods that these cells need to recover from radiation damage.

In the breast cancer, the most applied is the standard fractionation, or the daily irradiation dose of 2 Gy (Greys) five days a week for five weeks, to a total dose of $50 \mathrm{~Gy}$.

In certain cases it is necessary upon the completion of the whole breast irradiation, to apply an additional dose of irradiation only to the tumor bed, which is called a "boost" dose.

\section{Radiation therapy after neoadjuvant treatment}

In patients who receive neoadjuvant systemic therapy before surgical treatment (eg, chemotherapy, hormonal therapy, anti-HER-2 therapy) histopathological findings after surgery may vary from an unchanged tumor state (meaning tumor resistance to the conducted chemotherapy), to the complete clinical tumor regression after chemotherapy. According to the current guidelines, decisions related to postoperative radiotherapy should be based on the initial clinical tumor characteristics, regardless of the tumor response to systemic treatment, including tumors with complete histopathological response to neoadjuvant therapy (3). 


\section{Adjuvant radiation therapy after breast-conserving surgery}

The approach to adjuvant radiotherapy after breast sparing surgery primarily depends on the histological type of tumor. So, the indications for this type of treatment differ according to whether it is lobular carcinoma in situ, ductal carcinoma in situ or invasive breast cancer.

\section{Lobular carcinoma in situ (LCIS)}

Since the risk of invasive cancer after a breastconserving procedure for LCIS is significantly low, and the tumors have favorable histology and are successfully treated, the recommended treatment is breast conserving surgery followed by monitoring - mammography annually with clinical exams once or twice a year. NCCN doesn't recommend adjuvant radiation therapy in the case of lobular carcinoma in situ (3).

\section{Ductal carcinoma in situ (DCIS) (stage 0, Tis, NO, M0)}

The decision of the primary treatment of ductal carcinoma in situ (DCIS) primarily depends on the characteristics of the tumor histology. Although mastectomy provides maximum local control of the disease, in the case of limited disease (one quadrant), equal treatment results have been shown in patients who underwent mastectomy, and in patients who underwent breast conserving surgery followed by adjuvant radiotherapy $(4,5,6)$. In patients with large multicentric tumors, the treatment of choice is the mastectomy without the dissection of the lymph nodes.

Several major prospective randomized studies have shown that adjuvant radiotherapy in ductal carcinoma in situ reduces the appearance of local recurrence by $50 \%$ (both invasive and noninvasive), and the risk of recurrence is increased proportionately to the time after an operation $(4,5,6)$. There is an effort to identify a subgroup of patients with a very low risk DCIS where adjuvant radiotherapy may not be needed, but the results are controversial. According to some authors this pertains to tumors less than $1 \mathrm{~cm}$ in size, low grade, with negative operating edges, positive hormone receptors, and patient age greater than 60 yr. (6). Probably only the analysis of the biology of DCIS will bring more information about the need for additional adjuvant treatment of this dis- ease. There are ongoing studies of gene expressions using Oncotype DX DCIS recurrence score, thereby in combination with the other histological characteristics of the tumor a group of patients with DCIS could be marked as extremely low risk, who would not need adjuvant radiotherapy after surgery.

The definition of negative operating edge in the case of DCIS is still under discussion. A few years ago a consensus was reached that the margin greater than $10 \mathrm{~mm}$ is considered negative, but less than $1 \mathrm{~mm}$ positive, but the consensus has not yet been reached when it comes to values between these two. According to some authors, the greater the margin, the lower the incidence of local recurrence. On the other hand, resection edge of less than $1 \mathrm{~mm}$ in the area of the fibroglandular border (near the skin or thoracic wall), if a re-excision cannot be performed, may represent an indication for a greater "boost" dose of radiation to the described area. According to the recently published joint guidelines of the American Society of Surgical Oncology and the American Society for Radiotherapy and Clinical Oncology (ASO, ASTRO, ASCO) based on a comprehensive analysis of 20 studies with 7883 patients, $2 \mathrm{~mm}$ negative operating margins are considered adequate with DCIS ( with the implementation of postoperative radiotherapy) (Morro $\mathrm{M}$ et al., J Clin Oncol, published on line, Aug 2015). If the operating edge is less than $2 \mathrm{~mm}$, individual clinical decisions are required about the need for re-excision. Unlike DCIS, in invasive cancer a negative operating edge is now considered if there is no ink on the tumor margin of the histopathological tumor sample.

\section{Invasive cancer (stages I, IIA, IIB, or T3, N1, M0)}

In the case of invasive cancer, adjuvant radiotherapy is in the most cases necessary after breastconserving procedures. Radiation therapy actually allows breast-conserving surgery because it has been shown that a combination of both has the same therapeutic effect as a mastectomy. Of course, histopathological and biological features of the tumor determine the significance of radiotherapy. Overall it was shown that radiotherapy significantly reduces local recurrence and prolonges overall survival of patients. Long term (15 years) monitoring of patients in the EBCTGC studies have shown that radiation therapy reduc- 
es the incidence of local recurrence in the breast for approximately $30 \%$ (from $35 \%$ to $19 \%$ ), and significantly reduces mortality from breast cancer (7). It is believed that the adjuvant radiotherapy may be omitted in women older than 70 years with hormone-dependent tumor stage I (negative lymph nodes, T1 tumor). A study comparing two groups of patients of these characteristics, one of which received adjuvant hormonal treatment and radiation, and the second only hormonal treatment, showed no statistically significant difference between the groups in overall survival, survival till recurrence or need for mastectomy (8).

If patients received adjuvant chemotherapy containing anthracyclines or taxanes, radiotherapy treatment can only begin after the end of chemotherapy. There is no clear evidence whether to start first with adjuvant radiotherapy, but according to the guidelines, the treatment begins with adjuvant chemotherapy followed by radiotherapy $(9,10)$. To the current guidelines radiation therapy can be combined with anti-HER-2 therapy (trastuzumab) and with hormone therapy.

\section{Adjuvant radiation therapy after mastectomy}

According to current guidelines, radiation after mastectomy is indicated in patients with 4 or more positive axillary lymph nodes, but it should be considered also in patients with 1-3 positive lymph nodes. Specifically, it has been shown that prophylactic radiation of the thoracic wall significantly reduces the likelihood of locoregional recurrence in patients with 4 or more positive lymph nodes (11). Although consensus has not been reached when it comes to 1-3 positive lymph nodes, the recommendations are that patients with 1-3 affected lymph nodes and tumors larger than $5 \mathrm{~cm}$, or in the case of a positive resecting edge, be sure to consider adjuvant radiotherapy of the chest, supra - and infraclavicular lymphatic drainage, as well as possibly radiation of the ipsilateral internal mammary chain lymph nodes (category $2 \mathrm{~B}$ ). In the case of negative lymph nodes, thoracic irradiation is recommended in patients with tumors larger than $5 \mathrm{~cm}$ (T3) or positive resection edge (12).It is also recommended in these patients to consider radiation of the ipsilateral supraclavicular lymph nodes and ipsilateral internal mammary nodes. Radiation therapy after mastectomy is not recommended in patients with tumors smaller than $5 \mathrm{~cm}$, negative lymph nodes and negative resecting margins.

Nevertheless, retrospective analysis showed the reduction of recurrence risk in patients with negative lymph nodes, but with high-risk factors such as a close resection margin, tumors greater than or equal to $2 \mathrm{~cm}$, pre-menopausal status and lymphovascular invasion (13). Another study showed an increased risk of local recurrence in patients with negative nodes and triple negative disease, with tumors less than or equal to $5 \mathrm{~cm}$ (14). Hopefully, future molecular analysis of the tumor biology, will lead to the new prognostic and predictive parameters and specify the indications for radiotherapy.

\section{Local lymphatic drainage radiotherapy}

Axillary lymph nodes are traditionally divided into three floors. The first floor consists of lymph nodes located caudal to the lower limit of the great pectoral muscle, the second floor is located posterior to the small pectoral muscles, and the third floor is located medial and cranial of the pectoral muscles. Rotter nodes are often described as nodes that are located between the large and small pectoral muscle. The literature states that for an adequate assessment of the status of lymph nodes, the dissection of the first and second floor axillary lymph nodes is necessary, containing at least ten histologically analyzed lymph nodes $(15,16)$. In the event of clinically positive nodes in the second floor, the third floors axillary dissection is necessary.

In the case of four or more positive lymph nodes, the lymph drainage radiation, which includes the supraclavicular, infraclavicular, internal mammary lymph nodes, and axillary lymph nodes that are at risk, is absolutely indicated. Radiation of these regions is also recommended in the case where there are 1-3 positive nodes. Also, one should consider the radiation of one or more areas of the lymphatic drainage in patients who underwent mastectomy with T3 tumors (greater than $5 \mathrm{~cm}$ ) or positive margins (3).

Whenever possible, assessment of the status of the lymph nodes is done on the basis of histopathological analysis of the guard lymph node (sentinel node biopsy). In case of negative findings in the guard node, the tumor is classified as N0. However, the controversy remains over the 
issue of axillary dissection in case of positive findings in the guard node. ACOSOG 0011 study compared a group of patients who made only guard node dissection with a group which had axillary dissection. Patients had tumors stage T1/T2 and less than 3 positive nodes guards, and both groups were treated with breast conserving surgery and adjuvant radiotherapy of the whole breast. In this study there were no significant differences between the two groups, not in the percentage of local recurrence, survival to a recurrence, nor in overall survival (17). Based on these results, axillary dissection is not indicated in patients with less than three positive guard lymph nodes, tumor stage T1 or T2, who were not treated with neoadjuvant, but conserving surgery and radiotherapy of the whole breast. AMAROS randomized study showed that in patients with $\mathrm{T} 1$ and $\mathrm{T} 2$ tumors and positive sentinel lymph nodes, radiation therapy of the axillary region has the same effect as dissection (18). However, in this study the rate of axillary recurrence were in both groups less than expected, which to some extent affects the interpretation of results.

Regional lymph drainage radiotherapy in the case of isolated tumor cells (metastasis less than $0.2 \mathrm{~mm}$ ) and micrometastases in the sentinel node (metastasis size $0.2-2 \mathrm{~mm}$ ) is subject to debate. Still there are not enough studies related to this issue. Several studies have shown a connection between micrometastases in the sentinel lymph node with an increased number of relapses and reduced survival $(19,20,21)$. On the other hand, several retrospective studies point to a similar prognosis of patients with the presence of isolated tumor cells or micrometastases in sentinel lymph nodes of patients with a negative sentinel with emphasis that patients with positive sentinel were more often treated adjuvant, radiotherapy or systemic therapy $(22,23)$.

Due to this, when deciding on regional lymph drainage radiation in the case of micrometastases in the guard lymph node, attention should be payed to the histological features of the primary tumor. If these characteristics require adjuvant systemic chemotherapy (example, if there is a risk of systemic disease scattering), it is possible to conclude that the same applies to the nature of the disease in the lymph node. However, in making clinical decisions, it is necessary for each patient to individually weigh out the potential benefit for ra- diation therapy, in terms of the possible side effects that it brings (24).

\section{Radiation techniques and target volumes}

When there is an indication for radiation, the clinical target volumes for breast cancer are the breast or the thoracic wall and the areas of the regional lymphatic drainage. In order for the radiation to be properly implemented, it is necessary to achieve several conditions: daily reproducible position of the patient during radiation, dose homogeneity in the target volume and the maximum protection of the surrounding tissues and organs.

During radiation planning techniques known as three-dimensional conformal radiotherapy (3D-CRT) and intensity modulated radiotherapy form (IMRT) are used. Radiation planning is performed on the CT simulator. The patient is placed on a table, in a special rack for the breast, which ensures immobilization in the corresponding position, with the hands above the head, usually at an angle of 90 degrees to the axis of the body, thus ensuring the accuracy and reproducibility of the process. After the simulation, the development of the treatment plan begins, for which special software programs are used. The most commonly implemented form is intensity modulated radiotherapy - forward intensity modulated radiotherapy (fIMRT) in which the distribution of the dose is achieved with main bundles, and improves by adding additional conformaly formed bundles (25). The radiation is carried out by a linear accelerator (external radiation), and in certain cases can be implemented as internal radiation or brachytherapy, where various radioactive sources (mainly cesium and iridium) are used. Brachytherapy can be interstitial and intracavitary, depending on how the radioactive source in the breast tissue is inserted, or into the cavity formed upon tumorectomy, what word will be something later.

\section{Radiation protocols}

In most cases in the radiotherapy of breast cancer we use the so called standard protocol which involves the whole breast external radiation with or without regional lymph drainage area of a daily dose of 2 Gy, five days a week for five weeks, to a total dose of $50 \mathrm{~Gy}$. However, in recent years more and more protocols are being tested which use higher individual doses of radiation in a shorter 
overall period of time and with a reduction in the total dose of radiation (hypofractionation).

Several randomized clinical trials $(26,27,28,29)$ comparing hypofractionation whole breast radiation protocols (39-42.9 Gy, 2.6-3-3 Gy per fraction) with standard protocols 50 Gy in 25 fractions per 2 Gy. Data collected in the ten-year follow-up period in the START study, as well as in the Canadian study showed that the local disease control, as well as the aesthetic effect was similar in application protocols $42.5 \mathrm{~Gy}$ in 16 fractions over 3.2 weeks, compared with 50 Gy in 25 fractions over five weeks (29). START study also showed in the case of the simplified protocol a significantly lower incidence of certain side effects associated with normal breast tissue such as the contraction of the breast, the formation of telangiectasia, and edema of the breast (30). In the case of radiotherapy of the whole breast, NCCN recommends a dose of 45-50 Gy in 23-25 fractions or 40-42.5 Gy in 15-16 fractions, with preference for the latter protocol (data from the START study, convenience Protocol).

ASTRO (American Society for Radiation Oncology) guidelines do not recommend hypofractionation in patients younger than 50 years, patients after mastectomy, in cases where it is necessary to radiate the lymphatic drainage, if there is an indication for the "boost", and after adjuvant chemotherapy. Recommendation for now is only for patients aged 50 and older, tumor pT1 and 2, $\mathrm{N} 0$ after conservative breast surgery who did not receive chemotherapy.

In France, in older patients who for various reasons have problems with daily radiation, they routinely use a special scheme of $32.5 \mathrm{~Gy}$ in 5 weekly fractions per $6.5 \mathrm{~Gy}$. Study Institute Curie compared a group of patients treated by the above mentioned scheme with the group treated by standard fractionation. Although the results showed a similar local control, overall survival and diseasefree survival, given that there were great differences between the groups (the number of participants, age of the participants ...) and that they haven't thoroughly studied the toxicity, are subject to criticism (31). Currently there is an ongoing international randomized Phase II study SKAGEN that examines the role of hypofractionated Protocol in the radiation of the lymphatic drainage in cases of early breast cancer.

In patients with increased risk (younger than $50 \mathrm{~g}$, high tumor grade, positive resection edge), after a breast-conserving procedure and upon completion of adjuvant radiotherapy of the whole breast, the "boost" radiation of the tumor bed is indicated (32). "Boost" doses may be technically implemented with the help of photon or electron beams, or by using brachytherapy. Usual doses are 10-16 Gy in 2 Gy fractions.

\section{Accelerated partial breast radiation}

In the last few decades the approach to the treatment of localized breast cancer has dramatically changed. Breast sparing surgery in combination with adjuvant radiotherapy is the gold standard in the treatment of women with breast cancer early stage today. The above mentioned hypofractionated protocols where the entire breast is radiated in a shorter period of time and with higher daily doses, is a promising and relatively new approach in breast cancer radiotherapy. Accelerated partial breast radiation, which involves targeted radiation of only part of the breast, or places where the tumor was, is being tested as an alternative to whole breast radiation. It can be implemented by external radiation, brachytherapy, or in the form of intraoperative radiotherapy. Advantages of partial irradiation of the breast are: shorter duration of treatment, more focused radiation therapy, the possibility of giving high doses of radiation to a small volume and in shorter time periods. However, the follow-up of patients included in studies that have examined this form of treatment is relatively short, so we still cannot certainly say which subgroup of patients we can truly radiate adjuvant only part of the breast instead of the whole breast, or what are the long-term results of treatment in terms of reduction in local recurrence and quality of life. Additional investigations are being conducted.

\section{Brachytherapy}

This type of treatment is carried out with the help of radioactive sources that are placed in the breast tissue. Interstitial brachytherapy is carried out by using a catheter inserted into the breast tissue. This method is poorly distributed mostly because of the complicated procedure of inserting interstitial catheters. The appliecation is limited to a limited number of patients with early stage breast cancer (33).

Intracavitary brachytherapy in breast cancer is performed by inserting a catheter with an inflat- 
able balloon into a post-operative cavity. The best known applicator is MammoSite ${ }^{\circledR}$, and its advantage is its easy use, compared to a complicated procedure of interstitial catheter insertion. After MammoSite ${ }^{\circledR}$ there have been developments and other, more advanced models of this type of brachytherapy, the multi-lumen balloon, which is easier to adjust to the shape of post-operative cavity, such as for example Contura ${ }^{\circledR}$. SAVI ${ }^{\circledR}$ took the whole story a step forward with the introduction of peripheral catheters that surround the central, thus achieving higher dose flexibility.

Intracavitary brachytherapy can be carried out intraoperatively, so-called "open-cavity" technique, or as a separate procedure ("closed-cavity") up to ten weeks postoperatively. If applied postoperatively, it is inserted either through the postoperative scar, or through a separate incision. After insertion, the balloon is inflated with sterile saline to $4-5 \mathrm{~cm}$ in diameter with the addition of contrast. On CT images the balloon is designated as the target volume with the addition of a margin of $1 \mathrm{~cm}$. The usual dose of radiation is $34 \mathrm{~Gy}$ one time. The method is also used for the application of the "boost" dose to the tumor bed, after the whole breast radiation. Smith and colleagues retrospectively analyzed a group of patients who were treated by this method and have noticed that these patients were more likely to subsequently undergo mastectomy compared with patients who were treated with the standard protocol (33). Some studies have shown that accelerated partial breast radiotherapy can have in a number of cases side effects such as breast pain, fat necrosis and rib fractures (34).

\section{Intraoperative radiotherapy (IORT)}

Partial breast irradiation can be carried out via mobile accelerators (eg. Novac7 $\AA$ device that generates an electronic field strength 4-12 MeV, Intrabeam ${ }^{\circledR}$ that generates photons of low energy to $50 \mathrm{kV}$ ). Several studies have investigated and are still investigating the effect of intraoperative radiation therapy in a single dose of 20 , or $21 \mathrm{~Gy}$ to the tumorectomy site, compared to the classical adjuvant whole breast radiotherapy $(35,36)$. Monitoring of patients who are included in this study is still ongoing. One of the major drawbacks of intraoperative radiotherapy is that the radiation is applies immediately after surgery, when there are still no definitive pathologic findings. The study Target-A (Targeted Intraoperative Radiotherapy) used low energy of $50 \mathrm{kV}$ over a spherical applicator located in the tumor beds in low-risk patients. A single dose of $20 \mathrm{~Gy}$ was applied. After 5-year monitoring it has been shown that in $15 \%$ of patients, whole breast radiation had to be added based on the definitive histological findings. The emergence of local recurrence was $3 \%$ in the patients treated with IORT, to $1 \%$ in the control group who received standard protocol whole breast radiation (35). The single-institution ELIOT study (Milan) electrons were used for intraoperative radiotherapy. A single dose of $21 \mathrm{~Gy}$ intraoperatively was administered. 5-year monitoring of patients showed that the group treated with IORT had statistically significant more local recurrence $(5 \%)$, compared to $1 \%$ in the control group who had whole breast radiation $50 \mathrm{~Gy}$ in 25 fractions. It was concluded that the method should be approached with caution, we need careful selection of patients and an intensive program of quality control in this method of radiotherapy (36). Zhang and his colleagues recently published the results of a meta-analysis of 5415 patients who were treated with intraoperative radiotherapy which showed significantly more local recurrence in this group of patients than in patients treated with radiation of the whole breast standard protocol (37). The results of these studies of intraoperative radiotherapy for breast cancer still require further follow-up of patients, and considering the possible poorer treatment results in terms of increased incidence of local recurrence and caution when applying $(37,38)$.

Since the research on accelerated partial breast radiation therapy is still in progress, for now it is not recommended as a standard treatment for breast cancer. ASTRO guidelines suggest a possible application of partial breast irradiation using brachytherapy or external irradiation in selected patients with early stage breast cancer, where the results of partial radiation could be comparable with the results of standard radiotherapy of the whole breast (39). The candidates for adjuvant accelerated partial breast radiation would be women aged 60 or older, negative for BRCA mutation 1 and 2, with unifocal hormone dependent ductal invasive carcinoma stage T1N0, or similar tumor favorable histology. Also, it should not be invasive ductal component or LCIS, 
as neither positive resection edge. To the tumor bed 34 Gy in 10 fractions is applied twice daily when using brachytherapy, or 38.5 Gy in 10 fractions twice daily in case of external radiation. Some studies have shown that the ASTRO-know guidelines may not be good enough predicting increased incidence of local recurrence in the same breast after this method of radiation $(40,41)$. Several studies related to this issue are currently in progress. One of them is the large study NSABP B39 / RTOG 0413 which included 4300 patients, where they examined partial breast irradiation by external radiation at a dose of $34 \mathrm{~Gy}$ in 10 fractions, compared to the standard whole breast irradiation $50 \mathrm{~Gy}$ in 25 fractions. There is an ongoing IMPORT LOW study in the UK, with the involved 2018 patients, where they examined partial breast irradiation in relation to the radiation of the whole breast external radiation using IMRT technique. Therefore, the NCCN guidelines for now recommend accelerated partial breast radiotherapy primarily in the context of clinical trials. Surely, further molecular analysis of tumor biology will lead to the new prognostic and predictive parameters, and thus to the further personalization in the field of breast cancer radiotherapy.

\section{Radiation side effects}

The side effects of radiotherapy are divided into early and late. Early side effects occur during radiation and can last for a month upon the completion of radiation. They occur in the majority of patients during the second or third week of radiation as a consequence of damage to the epidermis. They are manifested by erythema of the skin in the radiated areas and dry and moist desquamation. They're harmless and temporary.

Late complications usually occur 3-6 months upon completion of radiation. These side effects are partly irreversible as a consequence of damage to the heart, lungs, blood and lymph vessels, the subcutaneous tissues, bones, and nerves. Heart failure is the only late complication that needs to be taken into account when setting the indications for radiation. Other late complications that should be mentioned are coronary artery damage resulting in ischemic heart disease, brachial plexus injury, radiation pneumonitis and pulmonary fibrosis, arm swelling, fractured ribs, and, rarely, the occurrence of secondary malignant tumors. Using conformal radiotherapy and maximum protection of healthy tissue significantly reduces the possibility of side effects and complications of breast cancer radiotherapy (42).

\section{Palliative radiotherapy}

The purpose of palliative radiation primarily is to eliminate / reduce the symptoms of advanced disease and, consequently, improve the quality of life of patients. The most common indications for this type of radiotherapy are pain and / or bleeding caused by advanced disease, neurological disorders caused by the presence of tumor transplants in the central nervous system, spinal cord compression, or pathological bone fracture. In breast cancer patients, palliative radiotherapy is usually applied to the bone, brain, ocular and retrobulbar metastasis. Also, palliative radiotherapy can be applied, in advanced cases of inoperable tumors alone or in combination with a systemic treatment. $(42,43)$.

Planning palliative radiation is done on the CT simulator, and usually carried out by means of two opposite fields. The total dose and fractionation depends on the radiation area and type of tumor. In doing so, we must take into account the previously irradiated regions of the body in order to avoid the application of excessive doses of radiation to the same area and thus prevent unwanted toxicity.

In the case of pain due to bone metastases, in most cases a single radiation dose of $8 \mathrm{~Gy}$ is recommended. For areas such as the cervical spine, the involvement of meninges, or, in the case of large nodal tumor weight, the recommended dose of 20 Gy distributed in five daily fractions per 4 Gy. In the case of large ulcerated and necrotic tumors, especially in patients of poor general condition, it is advisable to apply 36 Gy divided into 6 weekly fractions per 6 Gy (42).

\section{REFERENCES}

1. Fisher B, Anderson S, Bryant J, Magolese R, Deutsch $\mathrm{M}$, Fisher E, et al. Twenty-year follow-up of a randomized trial comparing total mastectomy, lumpectomy, and lumpectomy plus irradiation for the treatment of invasive breast cancer. N Engl J Med. 2002;347 (16);1233-41.

2. Owen JR, Ashton A, Bliss JM et al (2006) Effect of radiotherapy fraction size on tumour control in patients 
with early-stage breast cancer after local tumour excision: long-term results of a randomised trial. Lancet Oncol. 2006;7(6):467-71.

3. [NCCN-Internet]. 2016 [cited 6 May 2016]. Available from: https://www.nccn.org/professionals/physician_ gls/pdf/breast.pdf

4. Bijker N. Breast-conserving treatment with or without radiotherapy in ductal carcinoma in situ: Ten-year results of European Organization for Research and Treatment of Cancer Randomized phase III Trial 10853--A Study by the EORTC Breast Cancer Cooperative Group and EORTC Radiotherapy Group. J Clin Oncol. 2006;24(21):3381-7.

5. Fisher B, Dignam J, Wolmark N, Mamounas E, Costantino J, Poller W, et al.Lumpectomy and radiation therapy for the treatment of intraductal breast cancer: findings from national surgical adjuvant breast and bowel project B-17. J Clin Oncol 1998;16:441-52.

6. Vargas C, Kestin L, Go N, Krauss D, Chen P, Goldstein $\mathrm{N}$, et al. Factors associated with local recurrence and cause-specific survival in patients with ductal carcinoma in situ of the breast treated with breast-conserving therapy or mastectomy. Int J Rad Oncol Biol Phys. 2005;63(5):1514-21.

7. Early Breast Cancer Trialists' Collaborative Group (EBCTCG), Darby S, McGale P, Correa C, Taylor C, Arriagada $\mathrm{R}$, et al. Effect of radiotherapy after breastconserving surgery on 10-year recurrence and 15-year breast cancer death: meta-analysis of individual patient data for 10801 women in 17 randomized trials. Lancet. 2011;378(9804):1707-16.

8. Hughes K, Schnaper L, Berry D, Cirrincione C, McCormick B, Shank B, et al. Lumpectomy plus tamoxifen with or without irradiation in women 70 years of age or older with early breast cancer. $N$ Engl J Med. 2004;351(10):971-7.

9. Bellon J. Sequencing of chemotherapy and radiation therapy in early-stage breast cancer: updated results of a prospective randomized trial. J Clin Oncol. 2005; 23(9):1934-40.

10. Recht A, Come S, Henderson I, Gelman R, Silver B, Hayes D et al. The sequencing of chemotherapy and radiation therapy after conservative surgery for early-stage breast cancer. N Engl J Med. 1996;334(21): 1356-61.

11. Clarke M, Collins R, Darby S, Davies C, Elphinstone P, Evans $V$, et al. Effects of radiotherapy and of differences in the extent of surgery for early breast cancer on local recurrence and 15-year survival: an overview of the randomized trials. Lancet. 2005;366(9503):2087-106.

12. Nielsen H, Overgaard M, Grau C, Jensen A, Overgaard J. Study of failure pattern among high-risk breast cancer patients with or without postmastectomy radiotherapy in addition to adjuvant systemic therapy: long-term results from the Danish Breast Cancer Cooperative Group DBCG 82 b and c randomized studies. J Clin Oncol. 2006;24(15):2268-75.
13. Jagsi R, Raad R, Goldberg S, Sullivan T, Michaelson J, Powell S, et al. Locoregional recurrence rates and prognostic factors for failure in node-negative patients treated with mastectomy: implications for postmastectomy radiation. Int J Rad Oncol Biol Phys. 2005;62 (4):1035-9.

14. Abdulkarim B, Cuartero J, Hanson J, Deschenes J, Lesniak D, Sabri S. Increased risk of locoregional recurrence for women with T1-2N0 triple-negative breast cancer treated with modified radical mastectomy without adjuvant radiation therapy compared with breast-conserving therapy. J Clin Oncol. 2011;29(21): 2852-8.

15. Axelsson C, Mouridsen H, Zedeler K. Axillary dissection of level I and II lymph nodes is important in breast cancer classification. Eur J Cancer. 1992;28(8-9): 1415-8.

16. Kiricuta CTausch J. A mathematical model of axillary lymph node involvement based on 1446 complete axillary dissections in patients with breast carcinoma. Cancer. 1992;69(10):2496-501.

17. Giuliano A, McCall L, Beitsch P, Whitworth P, Blumencranz $\mathrm{P}$, Leitch A, et al. Locoregional recurrence after sentinel lymph node dissection with or without axillary dissection in patients with sentinel lymph node metastases: the American College of Surgeons Oncology Group Z0011 randomized trial. Ann Surg. 2010;252(3):426-32; discussion 432-3.

18. Donker M, van Tienhoven G, Straver M, Meijnen P, van de Velde C, Mansel R, et al. Radiotherapy or surgery of the axilla after a positive sentinel node in breast cancer (EORTC 10981-22023 AMAROS): a randomized, multicentre, open-label, phase 3 non-inferiority trial. Lancet Oncol. 2014;15(12):1303-10.

19. de Boer M, van Dijck JA, Bult P, Borm GF, Tjan-Heijnen VC. Breast cancer prognosis and occult lymph node metastases, isolated tumor cells, and micrometastases. J Natl Canc Ins. 2010; 102:410-25

20. Lupe K, Truong PT, Alexander C, Speers C, Tyldesley $\mathrm{S}$. Ten-year locoregional recurrence risks in women with nodal micrometastatic breast cancer staged with axillary dissection. Int J Rad Oncol Biol Phys. 2011;81: e681-e8.

21. Andersson Y, Frisell J, Sylvan M, de Boniface J, Bergkvist L. Breast cancer survival in relation to the metastatic tumor burden in axillary lymph nodes. J Clin Oncol. 2010;28:2868-73.

22. Houvenaeghel G, Classe JM, Garbay JR, Giard S, Cohen M, Faure C, et al. Prognostic value of isolated tumor cells and micrometastases of lymph nodes in early-stage breast cancer: a French sentinel node multicenter cohort study. Breast. 2014;23:561-6.

23. Gobardhan PD, Elias SG, Madsen EV, van Wely B, van den Wildenberg F, Theunissen EB, et al. Prognostic value of lymph node micrometastases in breast cancer: a multicenter cohort study. Ann Surg Oncol 2011; 18:1657-64. 
24. Tallet A, Lambaudie E, Cohen M, Minsat M, Bannier $\mathrm{M}$, Resbeut $\mathrm{M}$ et al. Locoregional treatment of early breast cancer with isolated tumor cells or micrometastases on sentinel lymph node biopsy. World J Clinl Oncol. 2016;7(2):243.

25. Beketic-Oreskovic L, Viculin T, Mataga V, Cehobasic A. Intensity modulated radiotherapy of breast cancer -comparison of fIMRT and iIMRT tecniques. Libri Oncol, 2014;42,1-3, 87-91.

26. START Trialists' Group, Bentzen SM, Agrawal RK, Aird EG, Barrett JM, Barrett-Lee PJ, et al. The UK Standardisation of Breast Radiotherapy (START) Trial B of radiotherapy hypofractionation for treatment of early breast cancer: a randomised trial. Lancet. 2008;371 (9618):1098-107.

27. START Trialists' Group, Bentzen SM, Agrawal RK, Aird EG, Barrett JM, Barrett-Lee PJ, et al Standardisation of Breast Radiotherapy (START) Trial B of radiotherapy hypofractionation for treatment of early breast cancer: a randomised trial. Lancet. 2008;9: 331-41.

28. Owen J, Ashton A, Bliss J, Homewood J, Harper C, Hanson J, et al. Effect of radiotherapy fraction size on tumour control in patients with early-stage breast cancer after local tumour excision: long-term results of a randomized trial. Lancet Oncol. 2006;7(6):467-71.

29. Whelan T, Pignol J, Levine M, Julian J, MacKenzie R, Parpia S, et al. Long-term results of hypofractionated radiation therapy for breast cancer. N Engl Jl Med. 2010;362(6):513-20.

30. Haviland J, Owen J, Dewar J, Agrawal R, Barrett J, Barrett-Lee P, et al. The UK Standardisation of Breast Radiotherapy (START) trials of radiotherapy hypofractionation for treatment of early breast cancer: 10year follow-up results of two randomized controlled trials. Lancet Oncol. 2013;14(11):1086-94.

31. Kirova Y, Campana F, Savignoni A, Laki F, Muresan $\mathrm{M}$, Dendale R, et al. Breast-conserving treatment in the elderly: long-term results of adjuvant hypofractionated and normofractionated radiotherapy. Int J Rad Oncol Biol Phys. 2009;75(1):76-81.

32. Werkhoven E, Hart G, Tinteren H, Elkhuizen P, Collette L, Poortmans Pm et al. Nomogram to predict ipsilateral breast relapse based on pathology review from the EORTC 22881-10882 boost versus no boost trial. Radiother Oncol. 2011;100(1):101-7.

33. Smith GL, Jiang J, Buchholz TA, Xu Y, Hoffman KE, Giordano SH, et al. Benefit of adjuvant brachytherapy versus external beam radiation for early breast cancer: impact of patient stratification on breast preservation. Int J Rad Oncol Biol Phys. 2014;88(2):274-84.

34. Akhtari M, Teh BS. Accelerated partial breast irradiation: advances and controversies. Chin J Canc. 2016;35;31 DOI: 10.1186/s40880-016-0095-1
35. Vaidya JS, Wenz F, Bulsara M, Tobias JS, Joseph DJ, Keshtgar M, et al. Risk-adapted targeted intraoperative radiotherapy versus whole-breast radiotherapy for breast cancer: 5-year results for local control and overall survival from the TARGIT-A randomised trial. Lancet. 2014;383(9917):603-13.

36. Veronesi U, Orecchia R, Maisonneuve P, Viale G, Rotmensz N, Sangalli C, et al. Intraoperative radiotherapy versus external radiotherapy for early breast cancer (ELIOT): a randomized controlled equivalence trial. Lancet Oncol. 2013;14(13):1269-77.

37. Zhang L, Zhirui Z, Xin M, Yang Z, Ma J, Chen X, et al. Intraoperative radiotherapy versus whole-breast external beam radiotherapy in early-stage breast cancer. A systematic review and meta analysis. Medicine (Baltimore) 2015;94(27):e1143.

38. Fisher CM, Rabinovitch R. Frontiers in radiotherapy for early-stage invasive breast cancer. J Clin Oncol. 2014;32:2894-901.

39. Smith B, Arthur D, Buchholz T, Haffty B, Hahn C, Hardenbergh $P$, et al. Accelerated Partial Breast Irradiation Consensus Statement From the American Society for Radiation Oncology (ASTRO). International J Rad Oncol Biol Physs. 2009;74(4):987-1001.

40. Shaitelman S, Vicini F, Beitsch P, Haffty B, Keisch M, Lyden M. Five-year outcome of patients classified using the American Society for Radiation Oncology (ASTRO) Consensus Statement (CS) Guidelines for the Application of Accelerated Partial Breast Irradiation (APBI): an analysis of patients treated on the American Society of Breast Surgeons (ASBS) MammoSite Registry Trial.Cancer.2010;116(20):4677-85.

41. Vicini F, Arthur D, Wazer D, Chen P, Mitchell C, Wallace $\mathrm{M}$, et al. Limitations of the American Society of Therapeutic Radiology and Oncology Consensus Panel Guidelines on the Use of Accelerated Partial Breast Irradiation. Int Jl Rad Oncol Biol Phys. 2011; 79(4):977-84.

42. Barrett A. Practical radiotherapy planning. London: Hodder Arnold; 2009.

43. Šamija M. Radioterapija raka dojke. In: Šamija M, Juzbašić S, Šeparović V, Vrdoljak VD. Tumori dojke. 1. izdanje. Zagreb: Medicinska naklada; 2007.

Corresponding author: Lidija Beketić Orešković, Department of Clinical Oncology, School of Medicine Univerity of Zagreb and Department of Radiotherapy and Internal Oncology, Univeritiy Hospital for Tumors, Universitiy Hospital Center Sestre milosrdnice, Ilica 197, Zagreb, Croatia.e-mail: lidijabeketicoreskovic@gmail.com 